THE FOLLOWING PAPERS ARE PUBLISHED FROM THE ANNUAL MEETING OF THE INTERNATIONAL MEDICAL SOCIETY OF PARAPLEGIA HELD AT STOKE MANDEVILLE HOSPITAL, AYLESBURY 1983

SESSION ON 'URODYNAMICS AND EFFECTS OF THE TREATMENT OF THE NEUROPATHIC BLADDER'

\title{
A CRITICAL REVIEW OF URODYNAMIC INVESTIGATIONS IN SPINAL CORD INJURY PATIENTS
}

By J. J. WyNdAele, M.D.

Department of Urology, Academical Hospital, De Pintelaan I85, B-900o Ghent, Belgium.

Summary. Urodynamic investigations carried out on 108 patients with an acute spinal cord injury were reviewed. Both clinical neurological examination and technical urodynamic investigations proved to be of great value in the management of the neuropathic bladder.

Key words: Spinal cord injury; Urodynamic investigations.

\section{Introduction}

The management of the neuropathic bladder is most important in the rehabilitation of patients with a spinal cord injury (Hackler I977; Warren et al., I98I).

Ample proof has been given that urodynamic investigations are indispensible for the classification and understanding of the dysfunction of the lower urinary tract due to any cause (Frimodt-Møller and Hald I972; Turner Warwick et al., I973; McGuire et al., I98 I; Anderson I983).

In a critical review of urodynamic investigations done in patients with an acute spinal cord injury we have attempted to find out how useful the data (given by these investigations), have been in the management of the neuropathic bladder in these patients.

\section{Materials and methods}

One hundred and eight patients ( 20 female, 88 male), with an acute spinal cord injury, were investigated. Their mean age was 35 ( 15 to 80) years.

The clinical neurological examination, related to the function of the lower urinary tract, was done weekly. It consisted of an assessment of the neurological level of the spinal lesion, of perineal sensation, of the cremasteric, bulbocavernosus and anal reflexes, and of the volitional control of the anal sphincter (Comarr I959; Bedbrook I98I).

Two hundred and fifty technical urodynamic investigations were done in these patients during their stay in the rehabilitation centre, six channel Disa urovideosystem being used.

Bladder, urethral and rectal pressures were recorded with microtransducers (Gaeltec) as described previously, (Wyndaele and De Sy, I979). 


\section{Results}

Value of the clinical neurological examination

The final data of this examination were compared with those of the technical urodynamics.

Correlation between the level of the spinal cord lesion and the type of neuropathic bladder that resulted are shown in Table I.

\section{TABLE I}

Correlation between the type of bladder dysfunction and the level of the spinal cord lesion

\begin{tabular}{lccl}
\hline $\begin{array}{l}\text { Level spinal } \\
\text { cord lesion }\end{array}$ & $\begin{array}{c}\text { Total No. } \\
\text { Patients }\end{array}$ & UMNB & LMNB \\
\hline Above DIO & 65 & $64(98 \cdot 5 \%)$ & I (I.5\%) \\
DII-DI2 & 20 & I2 $(60 \%)$ & $8(40 \%)$ \\
LI-L2 $_{\text {Below L }}$ & 15 & $6(40 \%)$ & $9(60 \%)$ \\
\hline
\end{tabular}

UMNB: upper motor neuron bladder

LMNB: lower motor neuron bladder

The type of neuropathic bladder was highly predictable with a spinal lesion above the level Dio but not below this level.

Correlation between the completeness of the neurological lesion of the lower urinary tract and the presence of normal perineal sensation together with volitional control of the anal sphincter were well shown in Ioo out of I08 patients (93 per cent).

Correlation between the activity of the striated urethral sphincter and the presence or absence of the bulbocavernosus reflex together with the anal reflex are compared in Table II. This correlated well in 97 per cent to 82 per cent.

TABLE II

Correlation between the activity of the external urethral sphincter and the bulbocavernosus $(\mathrm{BCR})$ and anal (AR) reflex

\begin{tabular}{lcc}
\hline & $\begin{array}{c}\text { BCR } \\
\text { AR present }\end{array}$ & $\begin{array}{c}\text { BCR } \\
\text { AR absent }\end{array}$ \\
\hline $\begin{array}{l}\text { urethral sphincter } \\
\text { activity present }\end{array}$ & $69(97 \%)$ & $4(18 \%)$ \\
$\begin{array}{l}\text { urethral sphincter } \\
\text { activity absent }\end{array}$ & $-(3 \%)$ & I8 (82\%) \\
\hline
\end{tabular}

\section{Value of the technical urodynamic investigations}

In our experience, there were five aspects in neuropathic bladder management where technical urodynamic investigations proved to be very important: 
I. Finding the best way of bladder emptying. For this purpose bladder emptying was practised repeatedly during urodynamic investigations.

In patients with a lower motor neuron bladder it helped to make best trigger area and how exactly bladder tapping had to be done. It permitted the selection of these patients with a high spinal cord lesion who are able to avoid dyssynergic contractions of the striated urethral sphincter provided they interrupt tapping as soon as bladder evacuation has started (Fig. I).

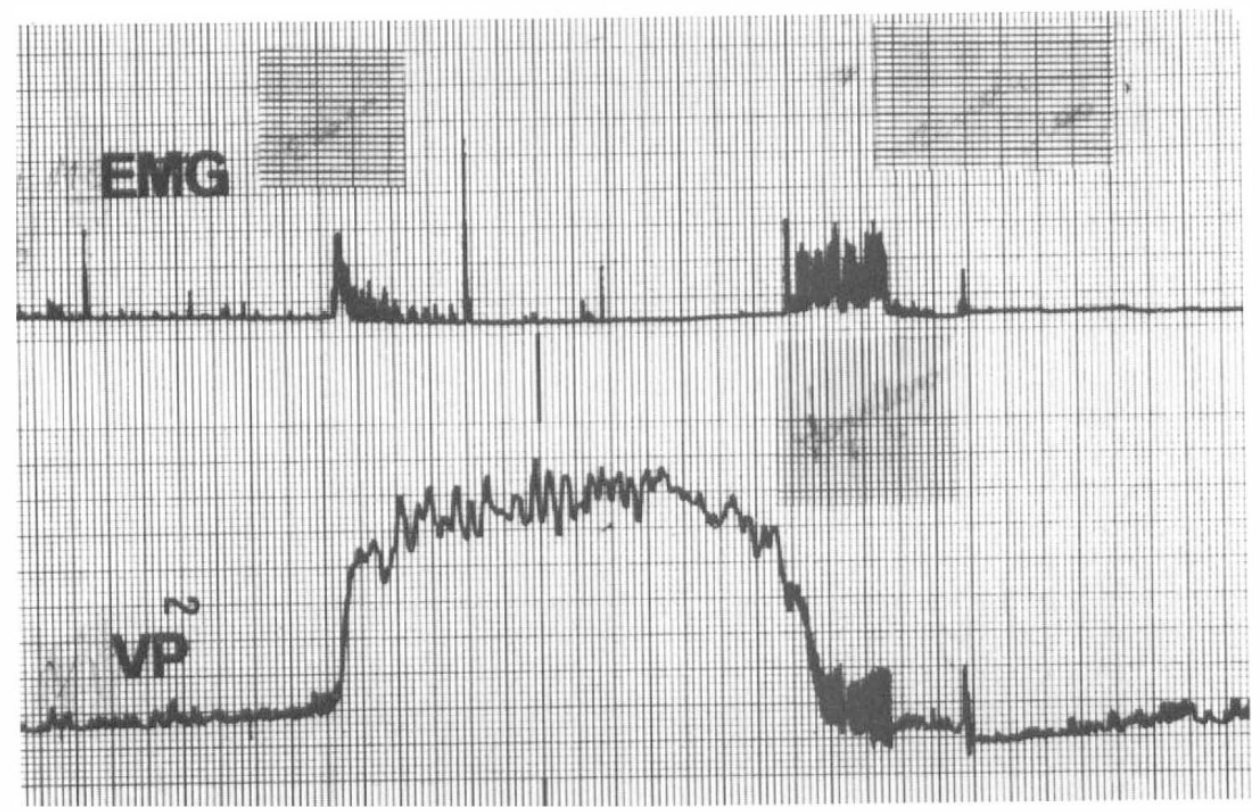

FIG I

EMG of the external urethral sphincter and vesical pressure (VP) during bladder contraction in a patient with a high spinal cord lesion who could avoid dyssynergy by interrupting tapotage as soon as he noticed micturition starting.

TABLE III

Occurrence of detrusor-external sphincter dyssynergia in patients with upper motor neuron lesions

\begin{tabular}{|c|c|c|c|}
\hline \multicolumn{2}{|c|}{ Spinal cord lesion } & \multirow{2}{*}{$\begin{array}{l}\text { Total No. } \\
\text { Patients }\end{array}$} & \multirow{2}{*}{$\begin{array}{l}\text { Patients with } \\
\text { dyssynergia }\end{array}$} \\
\hline Level & Type & & \\
\hline \multirow[t]{2}{*}{ Cervical } & incomplete & IO & 6 \\
\hline & complete & 7 & 5 \\
\hline \multirow[t]{2}{*}{ Thoracic } & incomplete & I & 0 \\
\hline & complete & 34 & $3 \mathrm{I}$ \\
\hline \multirow[t]{2}{*}{ Lumbar } & incomplete & 2 & 2 \\
\hline & complete & 4 & 4 \\
\hline
\end{tabular}


In patients with a lower motor neuron bladder it helped to make the Crédé manoeuvre or abdominal pressing as effective as possible.

2. Evaluation of the function of the bladder neck. For this purpose video-urodynamics proved to be important.

Radioscopy during urodynamics was also useful in localizing the microtransducers in the lower urinary tract and in diagnosing vesicorenal reflux or urethral pathology.

3. Evaluation of the function of the striated urethral external spinchter and especially the detection of detrusor sphincter dyssynergia. We found this phenomenon in patients at all levels of supranuclear spinal cord injury, both with complete and with incomplete lesions (Table III).

4. Selection of therapy. For this purpose technical urodynamics offer practically unlimited possibilities. This will be illustrated by some case studies:

\section{Patient I (Fig. 2)}

A woman of 52 years, tetraplegic since May I980, had been wrongly treated with large calibre Foley catheters for 5 months. She had almost completely lost urethral resistance, as demonstrated by the urethral pressure profile of I7/10/80. Consecutive urethral pressure measurements showed a slow but good effect of adrenergic drugs and intermittent catheterization. She became and remained completely continent after 4 months of treatment.

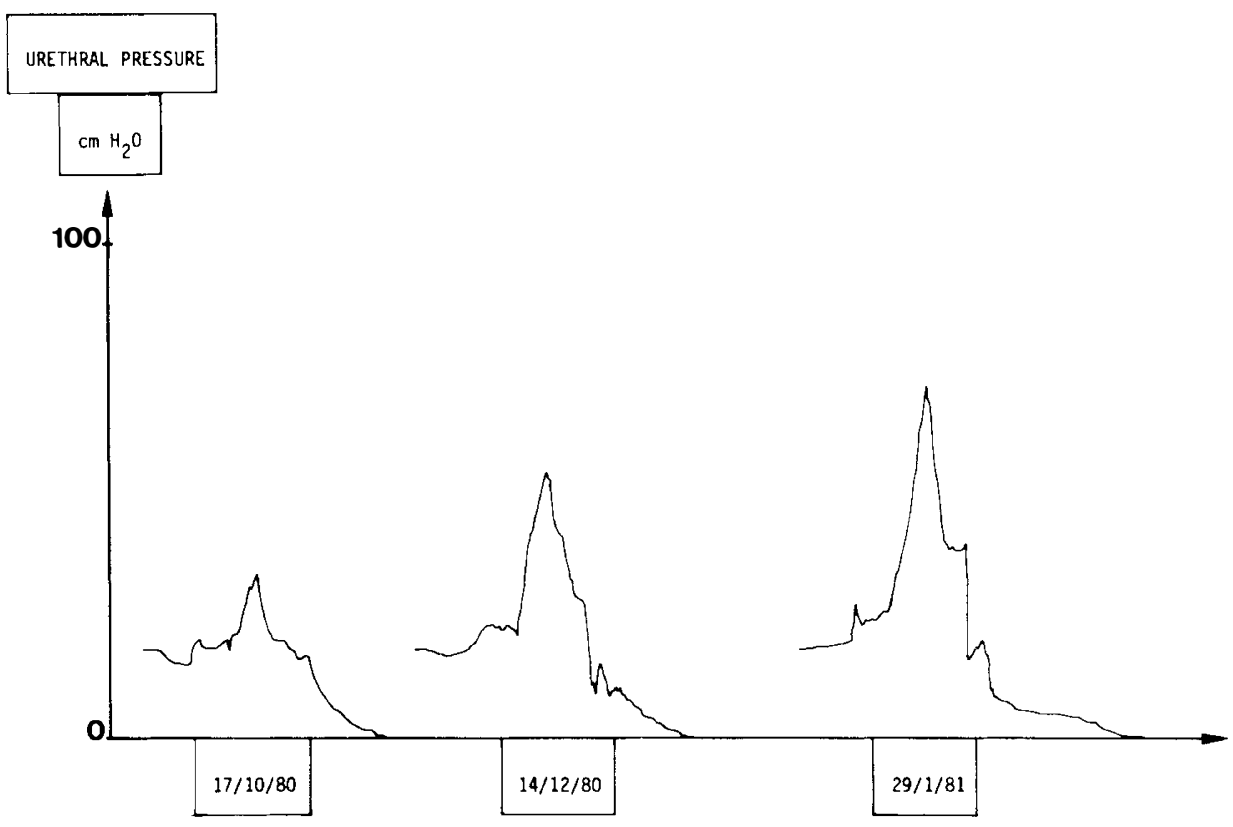

FIG. 2

Urethral pressure profiles in patient No. I. 


\section{Patient 2 (Fig. 3)}

A sphincterotomy was performed in a 17 years old paraplegic patient for incomplete bladder emptying. After the operation he continued to have a high residual although the urethral pressure after the sphincterotomy proved to be low. The main reason for the failure was an ineffective detrusor muscle contraction which was treated successfully with parasympaticomimetic drugs.

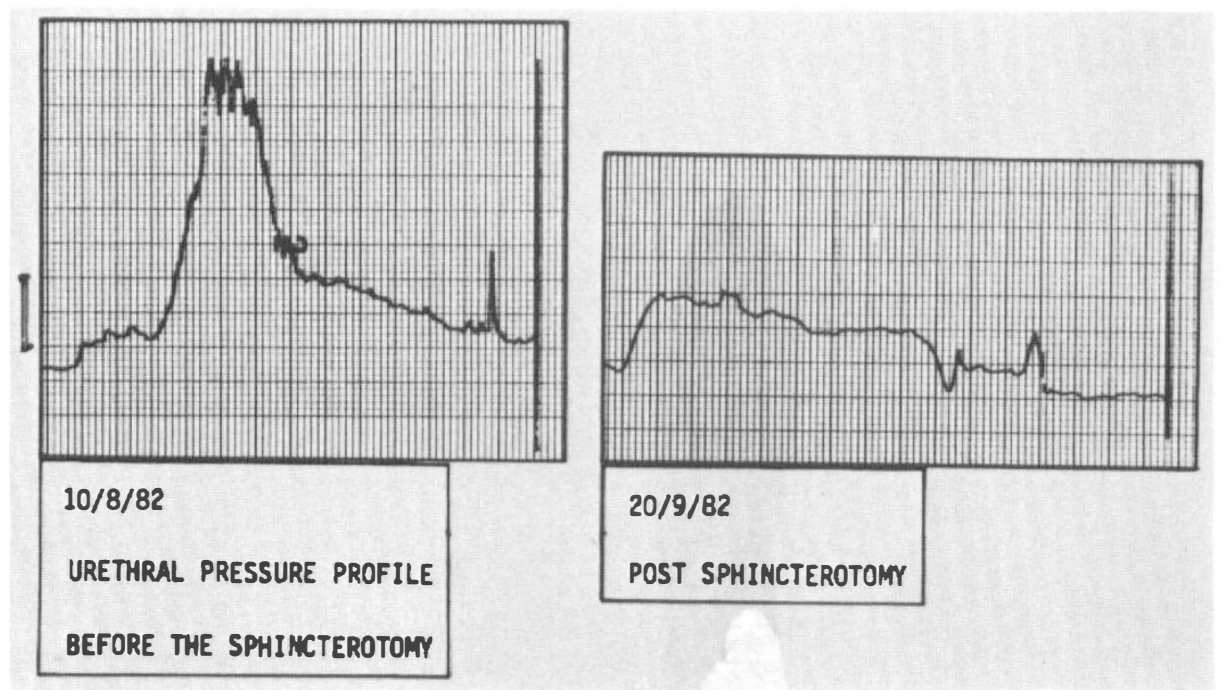

FIG. 3

Urethral pressure profile in patient No. 2. Vertical marker $=$ pressure $20 \mathrm{~cm}$ water.

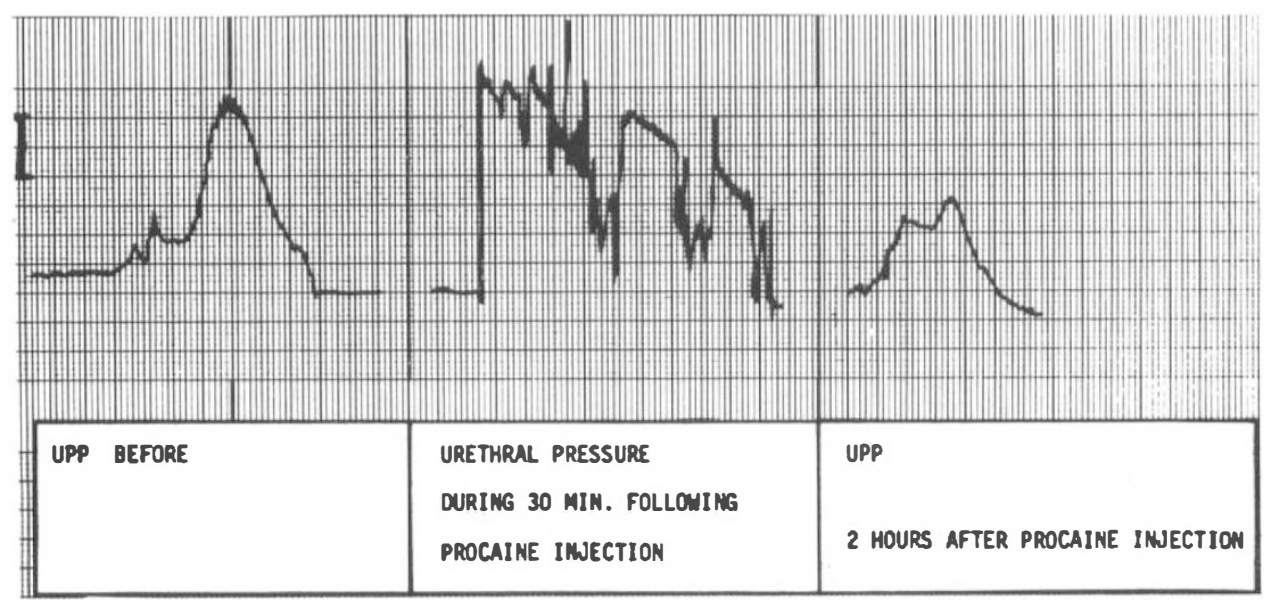

FIG. 4

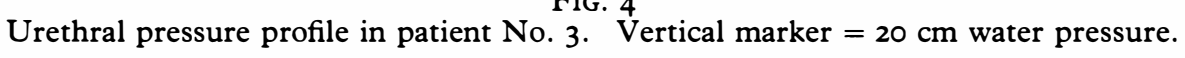




\section{Patient 3 (Fig. 4)}

Demonstrates the effect of procaine injection into the striated urethral sphincter on the urethral pressure profile of an I8-year-old paraplegic woman with extreme detrusor sphincter dyssynergia.

\section{Patient 4}

The effect of selective sacral (S) nerve blocks in the treatment of extreme bladder spasticity in an 26-year-old paraplegic woman is demonstrated in Figure 5.

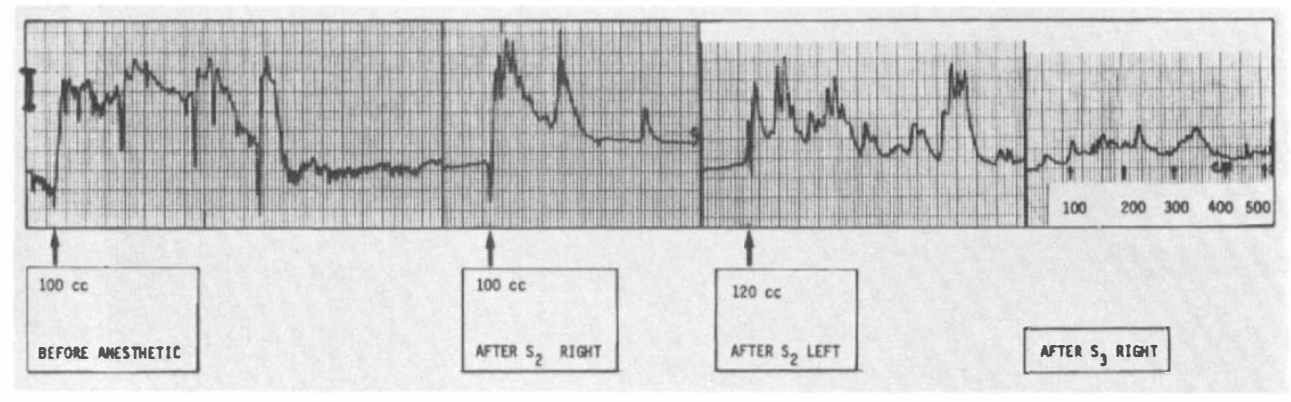

FIG. 5

Intravesical pressure during bladder filling in patient No. 4. Vertical marker $=20 \mathrm{~cm}$ water pressure. Horizontally bladder volumes in cc are given.

\section{Conclusion}

The clinical neurological examination continues to be important in the urological management of patients with spinal cord injury. In at least 80 per cent of the patients studied in this review it gave valuable basic information of the dynamics of the lower urinary tract, the type of neuropathic bladder, the completeness of the lesion and the activity of the external urethral sphincter. These data helped to guide the initial management of the neuropathic bladder in these patients. The results of the clinical examination proved to be reliable and correlated well with the findings of the technical investigations.

Technical urodynamic investigations gave an impressive amount of information about the dysfunction of the bladder and the urethra.

In practice, technical urodynamics were most helpful in finding the best way of bladder emptying and in the study of the external urethral sphincter, especially the detrusor-sphincter dyssynergia.

Video-urodynamics were almost indispensable for the evaluation of bladder neck function and in this respect radioscopy proved to be superior to radiography and endoscopy (Turner-Warwick and Whiteside 1976).

In the classification of therapeutic effects technical urodynamics were very adjustable. A good result of therapy during urodynamic investigations did not always mean an equally good outcome in daily practice.

Undoubtedly, the work that is done worldwide in this popular field will 
lead to a still better understanding and a more accurate management of what is happening in the lower urinary tract of spinal man.

\section{RÉSUMÉ}

On a passé en revue les investigations urodynamiques effectuées sur I08 malades qui souffraient d'une blessure aiguë de la moelle épinière. Tant l'examen neurologique clinique que les investigations urodynamiques techniques se sont montrés d'une grande valeur dans le traitement de la vessie neuropathique.

\section{ZUSAMMENFASSUNG}

Man hat eine Übersicht von urodynamischen Untersuchungen, die auf Pazienten mit schwerer Rückenmarkverletzung unternommen worden sind, ausgeführt. Sowohl die klinische neurologische Untersuchung als die technischen urodynamischen Untersuchungen haben sich gezeigt, von grosser Wert in der Pflege der neuropathischen Blase zu sein.

\section{REFERENCES}

ANDERSON, R. U. (I983). Urodynamic patterns after acute spinal cord injury: association with bladder trabeculation in male patients. F. Urol., I 29, 777-779.

Bedbrook, G. M. SIR (198I). The care and Management of Spinal Cord Injuries. p. I3-I 5. Springer Verlag, New York.

ComarR, A. E. (1959). The practical urological management of the patient with spinal cord injury. Brit. F. Urol., 31, I-46.

FRIMODT-MoLleR, C. \& HALD, T. (I972). Clinical urodynamics, methods and results. Scand. F. Urol. Nephrol., 6, Suppl. I5, I43-I 55.

HACKLER, R. H. (I977). A 25 year prospective mortality study in the spinal cord injury patient, comparison with the longterm living paraplegic. F. Urol., I I 7, 486-488.

McGuire, E. J., Woodside, J. R., Borden, T. A. \& Weiss, R. (I98I). Prognostic value of urodynamic testing in myelodysplastic patient. F. Urol., 126, 205-209.

Turner-Warwick, R., Whiteside, C. G., Arnold, E. P., Bates, C. P. Worth, P. H. L., Milroy, E. G. J., Webster, J. R. \& Weir, J. (I973). A urodynamic view of prostatic obstruction and the results of prostatectomy. Brit. F. Urol., 45, 63 I-645.

TURNER-WARWick, R. \& Whiteside, C. G. (1976). A urodynamic view of clinical urology. Recent advances in urology. Ed. W. F. Hendry, p. 44-74. Churchill Livingstone, Edinburgh.

Warren, J. W., Muncie, H. L. JR, Bergquist, E. J. \& Hoopes, J. M. (I98I). Sequelae and management of urinary infection in the patient requiring chronic catheterization. 7. Urol., 125, I-8.

WyNDAELE, J. J. \& DE Sy, W. A. (I979). Emploi de capteurs de pression miniatures pour examens urodynamiques. Compte rendu des communications au $2^{\circ}$ congrès $d u$ SIFUD Lyon Roger Bellon, Neuilly sur Seine. p. 255-264. 